\title{
The loT Evolution and its Impacts on Human Life
}

\author{
FROILAN D. MOBO
}

Philippine Merchant Marine Academy San Narciso, Zambales, Philippines.

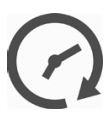

Article History

Published on 25 December 2018

The industry of technology facilitated numerous discovered daily. Various devices and appliances were created incredibly fast and turned into smart devices. It refers to the invention of gadgets where human life aspects are already controlled or totally affected with the technological advances. Nowadays, our day starts and ends up using gadgets and smart devices because it makes our life more comfortable and convenient. The loT has completely changed everything. Our mind is under the influence of advancement of new things. As we welcome the new world of connectivity, we are also losing the importance the human intelligence and labor. A new generationhas grown grownup with the presence of the internet where everything is just one click away and even the most basic task seems like 'magic' because of overly using smart devices. lot plays an important role in our lives, however human dependence on this advancement, in some areas, can replace the human mind. ${ }^{1}$

It is also a various system of all IT equipment enabled, vehicles, home apparatuses, and different things inserted with hardware, programming, sensors, RFID, and others networks, which empowers these things to associate, gather and trade information anyplace and whenever it includes broadening Internet availability past standard gadgets, for example, work areas, workstations, Tablet, smartphones and tablets, that can be connected anywhere. Installed with innovation, these gadgets can convey and connect over the Internet, and they can be remotely observed and controlled. With the entry of vehicles, a part of it, i.e. the Internet of Vehicles begins to acquire attention. ${ }^{2}$

It combines all technologies in the digital world In which all electronic devices are connected to each other in a local area forming a system which is further connected to other similar systems forming a much bigger network, for example connecting wired network acces a wirelessused network that can be used for office transactions.

CONTACT Froilan D. Mobo 1 froilanmbo@gmail.com Philippine Merchant Marine Academy San Narciso, Zambales, Philippines. (c) (1)

(c) 2018 The Author(s). Published by Oriental Scientific Publishing Company

This is an Open Access article licensed under a Creative Commons license: Attribution 4.0 International (CC-BY).

Doi: http://dx.doi.org/10.13005/ojcst11.04.02 
On a brighter side, loT can be applied to areas like business transactions that can fast track the communication and improve our system in order for us to understand and improve how we work in an loT Infrastructure. Another form of it is the Cloud computing, which we can access remotely, anywhere, for example, Google Apps or Good Docs where we and you can access your documents or data across a wireless network to a wired network realtime without experiencing difficulties. There are also some advantages in loT for example, using a home automation system where you can control the monitoring system of all your appliances at home whereever you are. Also, you can do remote testing of and load testing of your virtual servers using it for example, launching a stress test on your web servers remotely. ${ }^{3,4}$

Unskilled workers may end up losing their job and eventually lead to unemployment issues in society.

Applying Internet of Things in a particular country or cities is a big help imagine using unique centralized system that can minize traffic, detect crime easily or even accident can be detected in a realtime with a fast response from the respective supports. It can also help strengthen our economy through machines that works autonomously without needing human intervention. All the other support will greatly describe things that are made possible by the IoT. So Connected Home, Car, Mobile Phones and other appliances and device that can be connected a network in some way. Think of if a world of urbanized and industrialized equipped with those technologies that is interconnected together can simply help us in all our day to day activity. Even doing a laundry while doing a multi tasking activity at work and at home can be done simultaneously using this type of technology. We need to decide how much in favor of this advancement will control us. IoT improves the quality of life.

IoT can also solve major problems like Security Management that use sim cards or chips that can act as a sensors such as clothing with biometric sensors, facial recognition, footprint sensors, and more to increase the security of homes, offices and buildings so with these trends it can minimize security problems like robbery or even murder. Another good thing with the loT is can also interconnect with hospital equipment for health emergencies for example a patient with a heart ailment connected directly to the hospital can easily be addressed and save lives even in Road Traffic can minimized congested path by using an loT sim cards such as traffic lights, smartphones, cars, GPS devices, and cameras can be used to monitor traffic patterns, inform drivers of traffic situations can easily help our enforcers, government and the constituents. Another Thing is it can also help conserved energy consumption of home or work and in terms of agricultural matters it can also support by using a sensor that can detect the environmental problems. IoT is more sophisticated but it can lead to a better life and better business opportunities. ${ }^{5}$

\section{References}

1. Burgess, M. (2018, February 16). What is the Internet of Things? WIRED explains. Retrieved from https://www.wired.co.uk/ article/internet-of-things-what-is-explained-iot 2. Morgan, J. (2017, April 20). A Simple Explanation Of 'The Internet Of Things'. Retrieved from https://www.forbes.com/ sites/jacobmorgan/2014/05/13/simpleexplanation-internet-things-that-anyonecan-understand/\#772e900d1d09

3. The Google Cloud Difference - Grow Your
Business I Google Cloud. (n.d.). Retrieved from https://cloud.google.com/why-googlecloud/

4. What is Automated Testing? (n.d.). Retrieved from https://smartbear.com/learn/automatedtesting/what-is-automated-testing/

5. 5 Industry Problems That Can Be Solved by IoT. (2018, March 20). Retrieved from https:// www.controlany.com/5-industry-problemsthat-can-be-solved-by-iot/ 